\title{
Semblanza de la Dra. Bertha Bouroncle
}

\author{
Bertha Bouroncle, MD, biographical sketch
}

\author{
Víctor Vladimiro Rozas Olivera ${ }^{1,2}$ \\ ${ }^{1}$ Profesor de Medicina Clínica, Escuela de Medicina Universidad del Estado de Michigan, EE UU. \\ ${ }^{2}$ Profesor Honorario, Universidad Nacional San Antonio Abad de Cusco, Perú.
}

An Fac med. 2014;75(4):375-7 / doi: http://dx.doi.org/10.15381/anales.v75i4.10861

La Dra. Bertha A. Bouroncle GonzalezQuint, viuda del industrialista Andrew Pereny, una gigante de la hematología moderna, falleció el día 16 de agosto de 2013 en la ciudad de Columbus, Ohio. Ella nació en la ciudad de Trujillo, en el año 1919, hija del Dr. Luis H. Bouroncle y de la Sra. Carmela Gonzalez-Quint y fue la cuarta entre cinco hermanos.

La Dra. Bertha Bouroncle se graduó en el primer puesto de su promoción de la Facultad de Medicina de San Fernando de la Universidad Nacional Mayor de San Marcos, en el año 1948, y fue acreedora a una beca de posgrado. Ella eligió la Escuela de Medicina de la Universidad del Estado de Ohio, localizada en la ciudad de Columbus, Ohio. Su elección se debió a la presencia en dicha institución de dos renombrados hematólogos, los Dres. Charles Doan y Bruce Wiseman. La Dra. Bouroncle había tomado un interés especial por la hematología, debido a su trabajo como estudiante en un laboratorio de investigación de San Fernando. Al concluir su beca de un año, ella permaneció en Columbus y fue aceptada como Residente en el programa de Medicina Interna y Hematología, el cual concluyó como la primera mujer Jefe de Residentes. Inmediatamente después, en el año 1954, fue incorporada a la Escuela de Medici- na como Profesora Asistente, promovida a Profesora Asociada en el año 1957 y en el año 1970 a Profesora Principal, la primera mujer en el Estado de Ohio que alcanzó ese título.

La carrera profesional de la Dra. Bouroncle se caracterizó por ser una magnífica investigadora, una educadora de primera línea y un médico que abordaba a sus pacientes con compasión, respeto, consideración y conocimiento. Ella recibió el respeto y admiración de colegas en todo el mundo y de sus estudiantes y residentes, quienes asombrados por su ética de trabajo y habilidades como educadora, la honraron con numerosos galardones.

Las promociones médicas de graduados de los años 1974, 1975, 1976, 1977, 1979 y 1986 la eligieron como la mejor Profesora del Año y fue Miembro Honorario de la Promoción 1979. La Universidad del Estado de Ohio le confirió el Premio a la Enseñanza, en 1978. En 1984, la Escuela de Medicina la designó como Profesora del Año. En 1990 recibió el Premio Donald Unverferth por destacadas contribuciones académicas a la Medicina Interna y, en 1999, el Departamento de Medicina Interna le otorgó el Premio Earl N. Metz, por ser Médico Distinguida y en reconocimien-

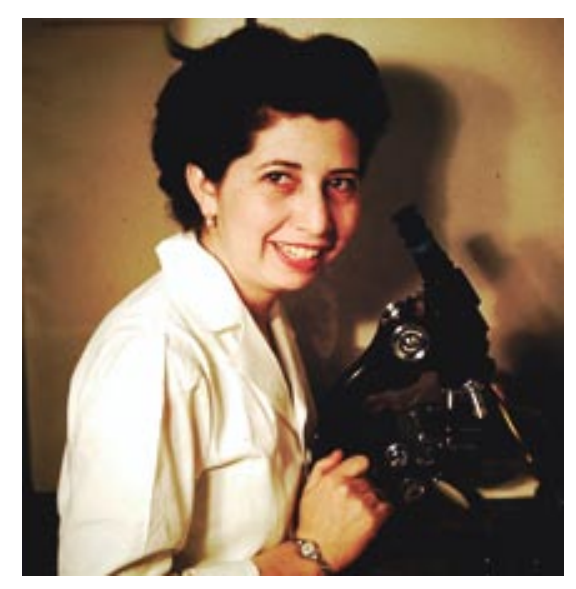

Figura 1. Dra. Bertha Bouroncle.

to a su dedicación a la investigación, la enseñanza y atención a pacientes. En el año 2001, la Universidad estableció el Premio Bertha Bouroncle para reconocer a distinguidos conferencistas.

Las contribuciones científicas de la Dra. Bouroncle al progreso de la hematología fueron extraordinarias. El Dr. Eric Kraut, Profesor de Medicina de la Universidad del Estado de Ohio, recordando a la Dra. Bouroncle dijo: "Ella tenía una energía increíble y curiosidad intelectual, y publicó en muchas áreas de la Hematología, desde linfomas y leucemias hasta enfermedades mielo- 


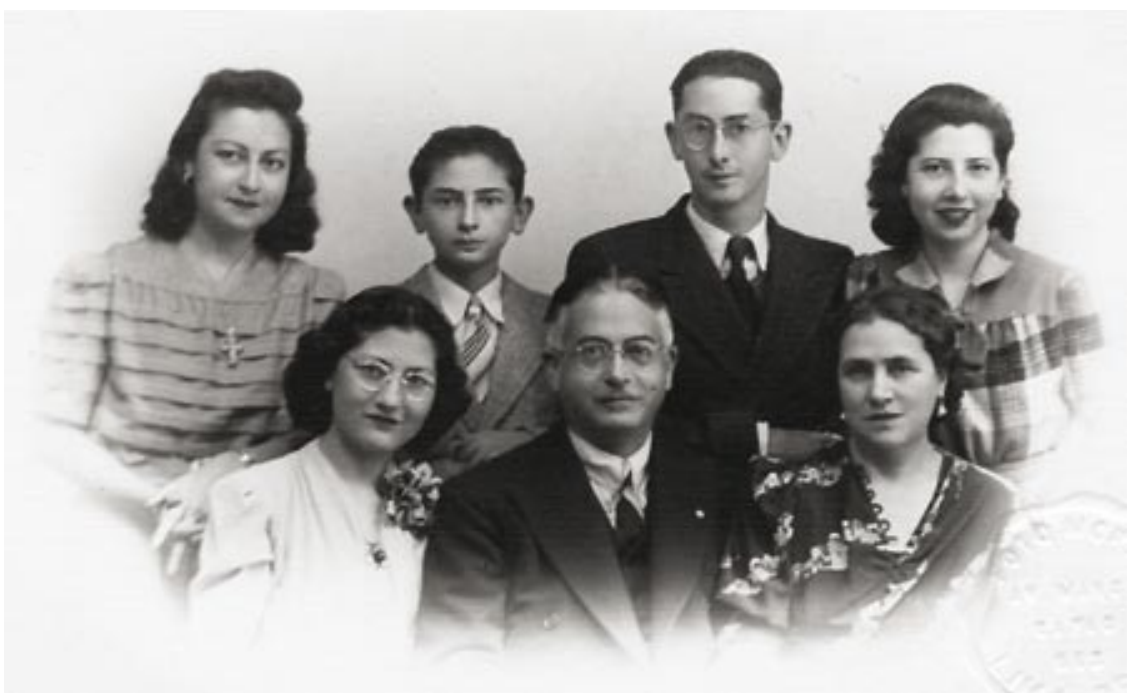

Figura 2. La Dra. Bertha Bouroncle con sus padres el Dr. Luis H. Bouroncle y la Sra. Carmela Gonzalez-Quint, sus hermanas Consuelo y Maruja y hermanos Luis y Antonio.

proliferativas. La mayor parte de sus artículos eran sobre experiencias clínicas, muy valiosas, ya que eran integrales y se concentraban en los problemas comunes con los cuales tratamos. La lectura de esos artículos en la actualidad dan un entendimiento mejorado de la enfermedad y sigue siendo muy provechosa".

Una de las contribuciones más notables de la Dra. Bouroncle fue el descubrimiento e identificación de un tipo de leucemia que subsecuentemente se denominó leucemia de células pilosas (hairy cell leukemia); luego, participó en el desarrollo efectivo de su tratamiento, y gracias a ella muchos pacientes han sobrevivido, lo que era hasta ese entonces una condición fatal. Muchos creen que, entre los diversos descubrimientos científicos, el trabajo de la Dra. Bouroncle sobre la leucemia de las células pilosas fue un logro alineado como el mayor de los descubrimientos científicos jamás registrados en la Universidad del Estado de Ohio. Las contribuciones científicas de la Dra. Bouroncle a la División de Hematología de la Escuela de Medicina han constituido uno de los pilares para que este centro obtenga un merecido prestigio internacional. No es exageración cuando el Dr. Eric Kraut dijo: "Uno podría resumir el legado de daba respeto, y esperaba mucho de todos aquellos que trabajaban alrededor de ella en el cuidado de los enfermos. Tenía la habilidad de hacer una crítica a sus colegas y pupilos sin hacerlos sentir mal. En una entrevista que ella concedió a un reportero de la revista Frontiers confesó que esencialmente ella era una persona tímida, pero que con los pacientes ella podía abrir su corazón. Becky Gibbins Whitaker, una enfermera del hospital universitario escribió: "Cada paciente era una persona para la Dra. Bouroncle; al entrar a las habitaciones de ellos, sabía algo personal de cada uno; al saludarlos sabía el nombre de su cónyuge, de su mascota, sus hijos, nietos, sobre algún evento importante en sus vidas, como un matrimonio, una graduación, etc. Esto era toda una proeza, considerando que ella trataba a cientos de pacientes. A pesar de ser muy ocupada, ella nunca parecía estar de prisa. Si ella tenía buenas o malas noticias que dar, siempre lo hacía con calma, tranquilidad y esperanza. Los pacientes la adoraban".

Con el espíritu altruista que la caracterizaba, la Dra. Bouroncle junto a

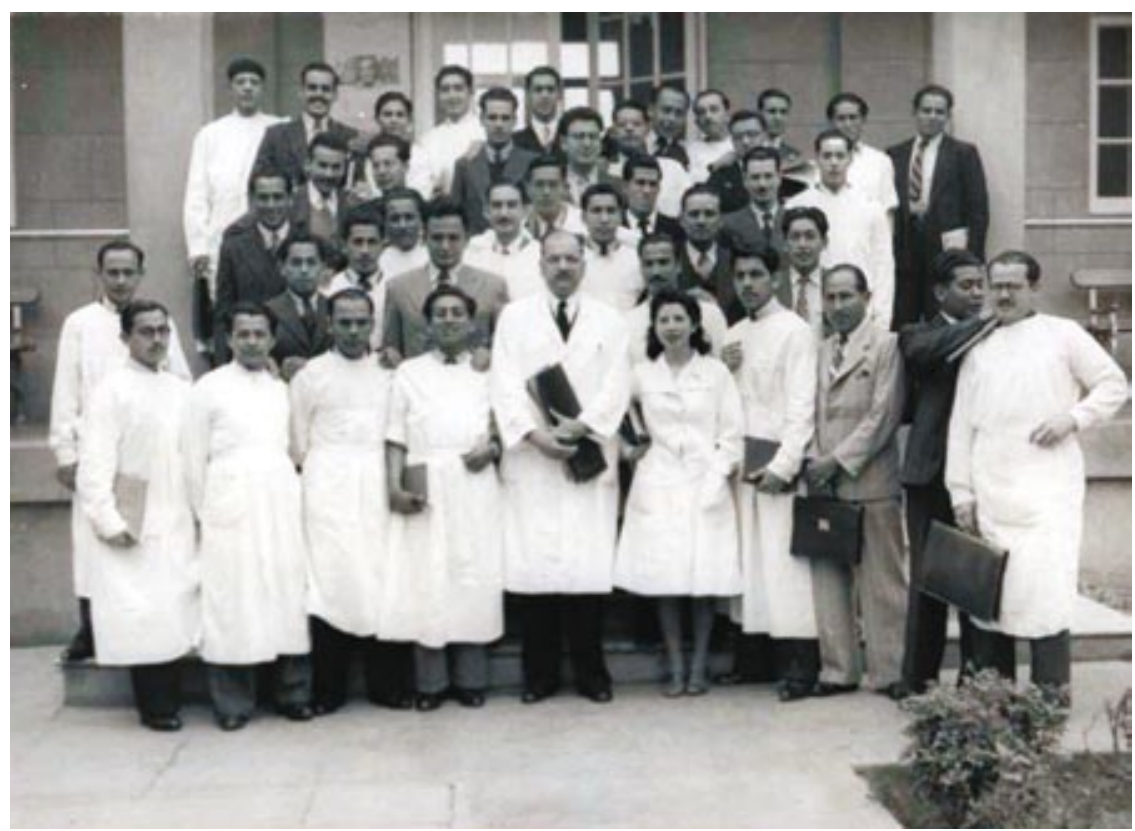

Figura 3. La Dra. Bouroncle con compañeros universitarios de San Fernando. 
su esposo el industrial Andrew Pereny hicieron una contribución económica significativa destinada a la investigación de enfermedades malignas en la Escuela de Medicina de la Universidad del Estado de Ohio, lo que hizo que se establezca la Cátedra Bertha Bouroncle y Andrew Pereny, cuyo Profesor Principal en la actualidad es el Dr. Michael Grever, Jefe del Departamento de Medicina e investigador de renombre.

La Dra. Bouroncle no se olvidó de su Alma Máter. Uno de sus últimos deseos fue la de contribuir a la investigación científica en San Fernando y para tal propósito destinó US $\$ 200,000.00$ (doscientos mil dólares), donación que se hará efectiva a través de la Asociación de Ex Alumnos de San Fernando, constituidos dentro de la Sociedad de Médicos Peruanos Residentes en los Estados Unidos (Peruvian American Medical Society - PAMS). Para esta ocasión

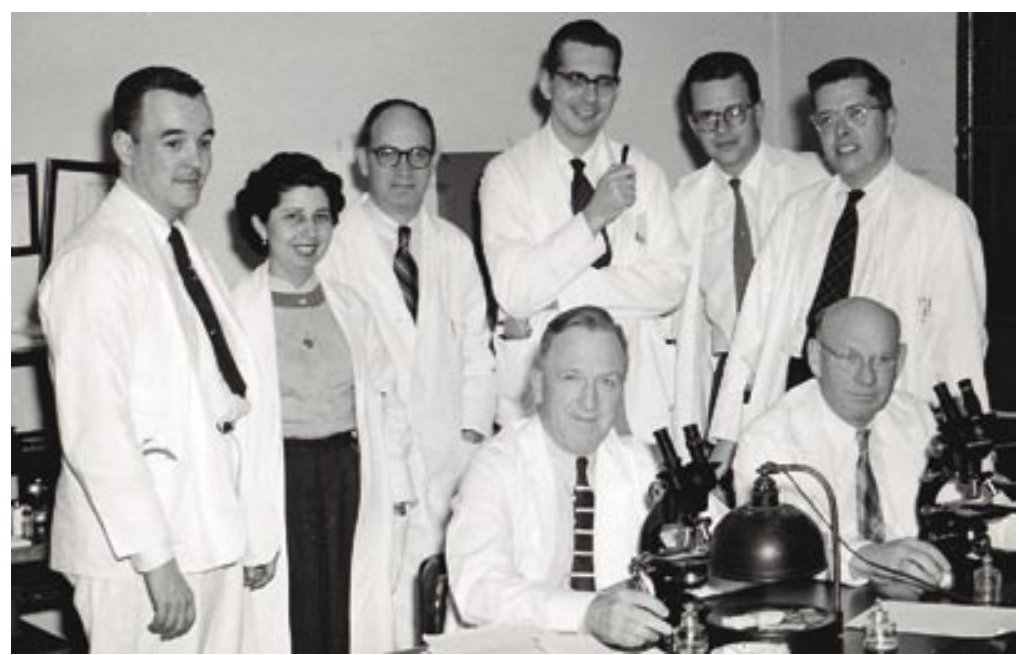

Figura 4. La Dra. Bouroncle con colegas de la División de Hematología, OSU.

en particular, San Fernando se vestirá de gala y con los brazos abiertos le extenderá el reconocimiento debido a una de sus más distinguidas graduadas.

\section{Correspondencia:}

Dr. Víctor Vladimiro Rozas Olivera

Correo electrónico: vrozas@voyager.net 